\title{
EXTRAÇÃO LÍQUIDO-LÍQUIDO APLICADA À REDUÇÃO DA ACIDEZ DE BIOCOMBUSTÍVEIS - EFEITO DO TEOR DE ÁCIDOS
}

\author{
A. A. MANCIO $^{1}$, I. V. CURCINO ${ }^{2}$, F. L. C. TEIXEIRA ${ }^{3}$, N. T. MACHADO ${ }^{4}$ \\ ${ }^{1}$ Universidade Federal do Pará, Discente do Programa de Pós-Graduação em Engenharia de \\ Recursos Naturais da Amazônia (PRODERNA) \\ ${ }^{2}$ Universidade Federal do Pará, Discente da Faculdade de Engenharia Química \\ ${ }^{3}$ Instituto Federal do Pará, Discente do Instituto Federal do Pará \\ ${ }^{4}$ Universidade Federal do Pará, Docente da Faculdade de Engenharia Química \\ e-mail para contato: dedeiamm@yahoo.com.br
}

\begin{abstract}
RESUMO - Os biocombustíveis gerados por craqueamento termocatalítico têm quantidade substancial de ácidos orgânicos, principalmente, ácidos carboxílicos. Portanto, o presente trabalho tem como objetivo principal estudar a aplicação da extração líquido-líquido como um processo alternativo para reduzir a acidez de biocombustíveis ácidos gerados por craqueamento termocatalítico, visando a prevenção de corrosão durante o processamento. Nos experimentos, biocombustíveis com diferentes números de ácidos totais foram submetidos a um contato com um solvente adequado para a realização da desacidificação. De acordo com os resultados obtidos, os biocombustíveis submetidos ao processo de extração líquido-líquido apresentam quantidades menores de ácidos orgânicos e o teor inicial de ácidos causa efeito significativo sobre o desempenho do solvente empregado para promover a desacidificação, bem como o teor de água presente no solvente combinado.
\end{abstract}

\section{INTRODUÇÃO}

O craqueamento catalítico de óleos vegetais envolve a pirólise de óleos vegetais na presença de catalisador sólido, o que pode melhorar o rendimento dos produtos [03]. $\mathrm{O}$ aquecimento das moléculas de óleos ou gordura provoca a quebra das cadeias carbônicas resultando numa mistura de hidrocarbonetos e alguns compostos oxigenados, como ácidos carboxílico, aldeídos, cetenos e acroleína (QUIRINO, 2006).

Uma desvantagem do craqueamento é a acidez do produto final obtido, devido principalmente à presença dos ácidos carboxílicos na mistura (QUIRINO, 2006). Em alguns casos, o produto final apresenta quantidades significativas de ácidos graxos que elevam a acidez do biocombustível, podendo assim danificar o motor que utiliza derivados de petróleo (PRADO e ANTONIOSI FILHO, 2009). 


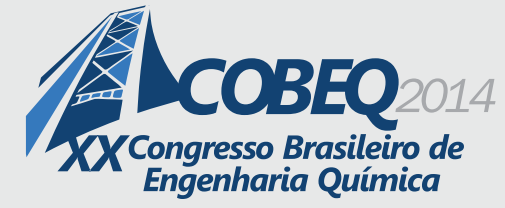

Para que ocorra o coprocessamento de biocombustíveis em uma instalação tradicional existente nas refinarias de petróleo, um melhoramento dos biocombustíveis é necessário, onde o oxigênio é parcial ou totalmente removido para estabilizar, reduzir a acidez e a viscosidade e, aumentar o valor energético dos óleos biocombustíveis (ZILNIK e JASBINSEK, 2012).

Têm-se relatos na literatura de que biocombustíveis foram melhorados por adição de água ou soluções aquosas levemente básicas para neutralizar ou aumentar o pH dos mesmos (ZILNIK e JASBINSEK, 2012). Moens et al. (2009) estudaram a neutralização e a estabilização do biocombustíveis produzidos por pirólise rápida e usaram o NAT como uma indicação da mudança na acidez. Eles concluíram que o tratamento do biocombustível bruto com metanol na presença de um catalisador sólido ácido não é um processo eficiente para a neutralização e estabilização dos biocombustíveis brutos. Outras técnicas estão sendo exploradas para reduzir o NAT destes biocombustíveis.

Como certos componentes presentes no biocombustível apresentam pontos de ebulição similares, a destilação não pode ser usada como uma técnica de separação para produzir químicos oxigenados distintos ou frações bem definidas de químicos. A extração por solvente a temperatura ambiente e pressão atmosférica foi sugerida como uma operação unitária promissora para remover os compostos oxigenados dos biocombustíveis (ZILNIK e JASBINSEK, 2012).

WANG et al. (2001) investigaram a remoção de ácidos (desacidificação) por extração líquido-líquido em destilado de frações pesadas da indústria de petróleo. Porém, nenhum solvente econômico e adequado foi encontrado, inviabilizando sua aplicação na indústria do petróleo. Os métodos antigos focam principalmente no método álcool-amônia em que foi empregado álcool etílico, álcool isopropílico e assim por diante como solvente e amônia como componente da desacidificação. A água foi geralmente adicionada para aumentar a massa específica do solvente combinado. Dados da refinaria de petróleo indicam que, quando o índice de acidez da matéria prima é menor do que $0,5 \mathrm{mg} \mathrm{KOH} / \mathrm{g}$, o processo de refino por extração líquido-líquido pode tornar o índice de acidez do óleo refinado inferiores a 0,03 $\mathrm{mg} \mathrm{KOH} / \mathrm{g}$.

Neste contexto, o desenvolvimento deste trabalho tem como objetivo principal investigar o efeito do teor de ácidos graxos livres, bem como o efeito do solvente combinado e o efeito do teor de água presente no solvente combinado sobre o processo de desacidificação através de extração líquido-líquido de ácidos graxos livres presentes no produto líquido orgânico obtido por craqueamento termocatalítico de óleo de palma bruto realizado em uma planta piloto de craqueamento termocatalítico (FEQ/ITEC/UFPA).

\section{MATERIAL E MÉTODOS}

Duas amostras de Produto Líquido Orgânico (PLO) com elevado número de ácidos totais e oriundas do craqueamento termocatalítico do óleo de palma em escala piloto foram utilizadas na investigação da desacidificação do PLO através da extração líquido-líquido empregando dois solventes combinados, sendo um destes constituído por uma combinação de álcool etílico (99,5\%) e água destilada e o outro composto de álcool isopropílico (99,8\%) e água destilada. 


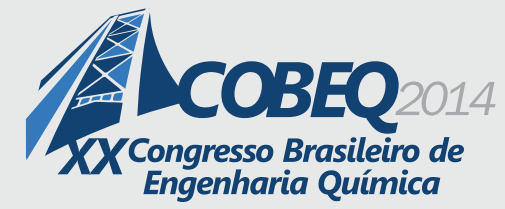

Antes de iniciar a desacidificação por extração líquido-líquido, determinou-se o número de ácidos totais (NAT) das duas amostras de PLO de acordo com método oficial da ASTM D 974, os quais os valores estão dispostos na Tabela 1.

Tabela 1 - Número de ácidos totais das mostras de PLOs empregadas como alimentação na desacidificação por extração líquido-líquido

\begin{tabular}{cc}
\hline Alimentação & NAT (mg KOH/g) \\
\hline A & 46,47 \\
B & 51,56 \\
\hline
\end{tabular}

\subsection{Desacidificação por extração líquido-líquido}

Uma vez determinado o número de ácidos totais das amostras (PLO), iniciou-se os experimentos de desacidificação por extração líquido-líquido das mesmas, em que as seguintes variáveis de processo foram alteradas: (1) teor de ácidos graxos livres presente na alimentação; (2) solvente combinado e (3) teor de água presente nos solventes combinados. Para a realização dos experimentos do presente trabalho, manteve-se constante a temperatura $\left(25^{\circ} \mathrm{C}\right)$ e a razão mássica alimentação/solvente combinado de 1/1.

Efeito do teor inicial de ácidos graxos livres: com o objetivo de avaliar o efeito do teor de ácidos graxos livres presentes na alimentação sobre o processo de desacidificação por extração líquido-líquido, foram selecionadas duas amostras de PLO, A e B, com número de ácidos totais diferentes.

Efeito do solvente combinado: com o objetivo de avaliar o efeito do solvente combinado sobre o processo de desacidificação por extração líquido-líquido, foram selecionados dois solventes diferentes: álcool etílico e álcool isopropílico. Quantidade de água pré-estabelecida foi adicionada a ambos os solventes a fim de aumentar a massa especifica dos mesmos e, dessa forma, conseguirmos favorecer a formação das duas fases que é fundamental na extração líquidolíquido.

Efeito do teor de água presente nos solventes combinados: com o objetivo de avaliar o efeito do teor de água presente nos solventes combinados sobre o processo de desacidificação por extração líquido-líquido, foram preparadas cinco soluções (álcool + água) com teores de água diferentes, tanto para o álcool etílico como para o álcool isopropílico, conforme apresentado na Tabela 2.

Após a preparação das soluções (solvente combinado), pesou-se a massa de solvente combinado e a massa de produto líquido orgânico a fim de se ter uma razão mássica de alimentação/solvente combinado de 1/1. Em um vaso agitado de aço inoxidável e encamisado com capacidade de $2 \mathrm{~L}$ acoplado a um banho ultra-termostático com controle de temperatura, adicionou-se, primeiramente, o produto líquido orgânico e, em seguida, adicionou-se a massa de solvente combinado. Em seguida, agitou-se o material adicionado ao vaso por um período de 60 minutos para que o solvente combinado tivesse um contato adequado com a alimentação. Após o 
término da agitação, a mistura foi introduzida em um funil de separação e ficou em repouso até alcançar a separação total das fases. Neste estudo, cada experimento permaneceu em repouso por um período de $24 \mathrm{~h}$.

Tabela 2 - Teor de água no solvente combinado empregado em cada experimento

\begin{tabular}{ccc}
\hline \multirow{2}{*}{ Experimentos } & \multicolumn{2}{c}{ Teor de água no solvente combinado (\%) } \\
\cline { 2 - 3 } & Etanol/Água & Isopropanol/Água \\
\hline Exp. 1 & 10 & 20 \\
Exp. 2 & 15 & 25 \\
Exp. 3 & 20 & 30 \\
Exp. 4 & 25 & 35 \\
Exp. 5 & 30 & 40 \\
\hline
\end{tabular}

Passada o período de repouso, separou-se a fase leve da fase pesada. A fase leve (rafinado) é caracterizada pela presença de PLO desacidificado contendo um pouco de solvente combinado, enquanto a fase pesada (extrato) é caracterizada pela presença de solvente combinado e compostos ácidos extraídos do PLO. Em seguida, determinou-se o número de ácidos totais, conforme o método padrão da ASTM D 974 de ambas as fases, rafinado e do extrato.

\section{RESULTADOS E DISCUSSÃO}

\subsection{Efeito do teor inicial de ácidos graxos livres sobre a desacidificação}

Duas amostras de PLO constituídas por diferentes teores de ácidos graxos livres, amostras A (46,47 mg KOH/g) e B (51,56 mg KOH/g), foram submetidas a desacidificação por extração líquido-líquido com a finalidade de avaliar o efeito da variável teor inicial de AGLs sobre a remoção dos AGLs e, os resultados são apresentados nas Tabelas 3 e 4 e Figuras 1 e 2.

A partir dos resultados, observou-se que o teor de AGLs presente na alimentação apresenta um efeito direto na remoção dos ácidos, pois um incremento no teor de ácidos promove uma redução no desempenho do solvente combinado em relação a quantidade relativa de ácidos removidos, ou seja, o quando o número de ácidos totais do PLO saiu de 46,47 mg KOH para $51,56 \mathrm{mg} \mathrm{KOH}$, verificou-se que para ambos os solventes combinados e os cinco teores de águas presente nos mesmos a quantidade relativa de AGLs removidos reduziu, conforme mostrado na Figura 1 e 2. 
Tabela 3 - Valores de número de ácidos totais do rafinado para diferentes teores de água no solvente combinado (álcool etílico + água) a $25^{\circ} \mathrm{C}$

\begin{tabular}{ccccc}
\hline \multirow{2}{*}{$\begin{array}{c}\text { Teor de água } \\
\text { (\%) }\end{array}$} & \multicolumn{2}{c}{ NAT do rafinado (mg KOH/g) } & \multicolumn{2}{c}{ Ácidos removidos (\%) } \\
\cline { 2 - 5 } & A Amostra & B & A & B \\
\hline 10 & 20,3127 & 26,6901 & 56,2842 & 48,2349 \\
15 & 21,7829 & 27,2636 & 53,1202 & 47,1226 \\
20 & 27,1883 & 32,763 & 41,4870 & 36,4566 \\
25 & 24,8946 & 35,8142 & 46,4234 & 30,5388 \\
30 & 26,1161 & 36,6722 & 43,7945 & 28,8747
\end{tabular}

Amostras: $\mathrm{A}=46,47 \mathrm{mg} \mathrm{KOH} / \mathrm{g}$; $\mathrm{B}=51,56 \mathrm{mg} \mathrm{KOH} / \mathrm{g}$.

Tabela 4 - Valores de número de ácidos totais do rafinado para diferentes teores de água no solvente combinado (álcool isopropílico + água) a $25^{\circ} \mathrm{C}$

\begin{tabular}{ccccc}
\hline \multirow{2}{*}{$\begin{array}{c}\text { Teor de água } \\
\text { (\%) }\end{array}$} & \multicolumn{2}{c}{ NAT do rafinado (mg KOH/g) } & \multicolumn{2}{c}{ Ácidos removidos (\%) } \\
\cline { 2 - 5 } & A & B & A & B \\
\hline 20 & 19,6209 & 29,498 & 57,7731 & 42,7890 \\
25 & 23,3694 & 30,5361 & 49,7058 & 40,7756 \\
30 & 24,8946 & 30,4015 & 46,4234 & 41,0367 \\
35 & 25,8904 & 34,633 & 44,2803 & 32,8297 \\
40 & 27,7457 & 36,9774 & 40,2874 & 28,2828 \\
\hline
\end{tabular}

Amostras: $\mathrm{A}=46,47 \mathrm{mg} \mathrm{KOH} / \mathrm{g}$; $\mathrm{B}=51,56 \mathrm{mg} \mathrm{KOH} / \mathrm{g}$.

\subsection{Efeito do solvente combinado sobre a desacidificação}

Os resultados mostram que para os mesmos teores de água (20, 25 e 30\%) em ambos os solventes combinados, o melhor é aquele formado por álcool isopropílico e água, pois para esses teores de água e esse solvente, a quantidade relativa de ácidos removidos foi levemente maior quanto comparado com os valores obtidos para álcool etílico e água. Em contrapartida, o álcool etílico com 10 e $15 \%$ de água consegue promover a separação das fases extrato e rafinado, fato que o álcool isopropílico com os mesmos teores de água não consegue promover. A 10 e 15\% de água, o solvente combinado composto de álcool etílico e água consegue remover quantidades relativas semelhantes e até mesmo superiores quando comparado ao solvente combinado álcool isopropílico contendo $20 \%$ de água, conforme apresentado na Tabela 2 e 3. Porém, de forma geral, observou-se que ambos os solventes combinados capazes de reduzir o número de ácidos totais, indicando que houve remoção dos componentes ácidos presentes no PLO. 


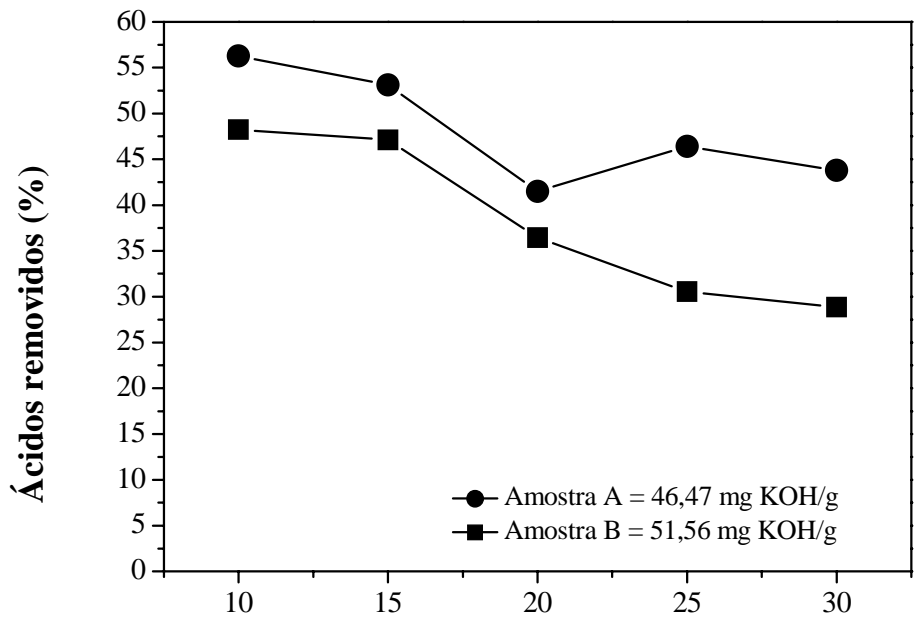

Teor de água no solvente combinado (\%)

Figura 1 - Efeito do teor de ácidos graxos livres sobre a remoção de ácidos empregando solvente combinado (álcool etílico + água).

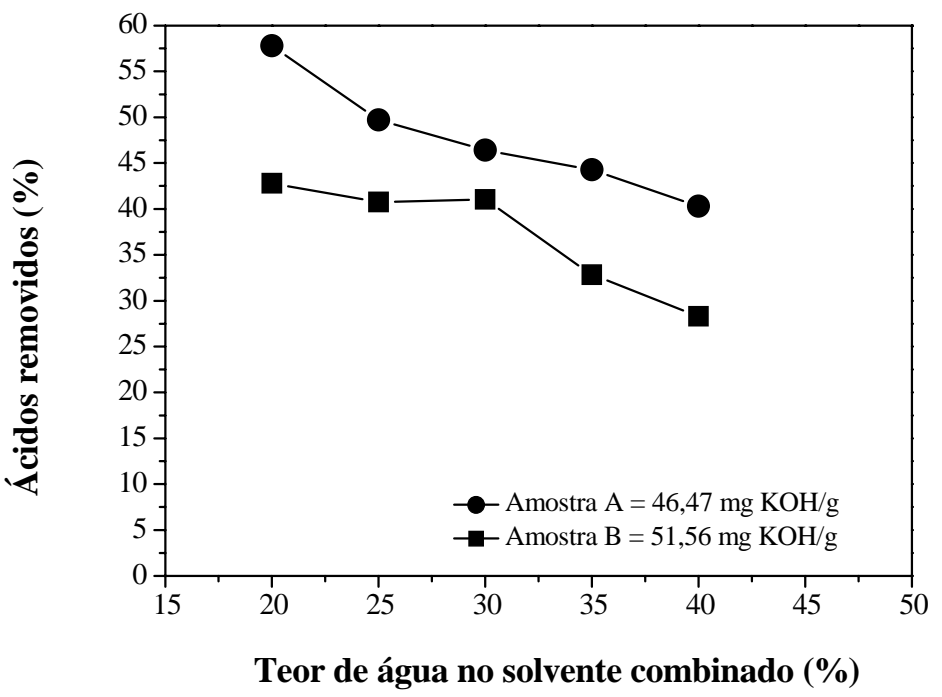

Figura 2 - Efeito do teor de ácidos graxos livres sobre a remoção de ácidos empregando solvente combinado (álcool isopropílico + água). 


\subsection{Efeito do teor de água presente no solvente combinados sobre a desacidificação}

De acordo com as tabelas e as figuras dispostas acima, observou-se que os cinco teores de água presente no solvente combinado tem um efeito significativo sobre a remoção dos ácidos graxos livres presente no PLO, independente do teor de ácidos graxos livres na alimentação e do solvente combinado empregado no presente trabalho. Além disso, quanto maior o teor de água no solvente combinado, seja álcool etílico ou álcool isopropílico, menor é o efeito dos mesmos sobre a remoção dos AGLs, indicando que a quantidade de água deve ser a mínima possível para não desfavorecer o processo de desacidificação através de extração líquido-líquido. Essa quantidade mínima é útil apenas para aumentar a massa especifica do solvente, como pode ser visualizado nas Figuras 3 e 4, a fim de separar as duas fases coexistentes (rafinado e extrato) no processo em questão, conforme foi feito por WANG et al. (2001). Em relação a este fato, o teor de água mínimo, encontrado no presente trabalho, para que a formação de duas fases (rafinado e extrato) fosse observada, foi diferente para os dois solventes empregados na desacidificação por extração líquido-líquido do PLO. O álcool etílico e o álcool isopropílico necessitaram de no mínimo 10\% e $20 \%$ de água, respectivamente, para verificarmos a coexistência da fase rafinado e da fase extrato.

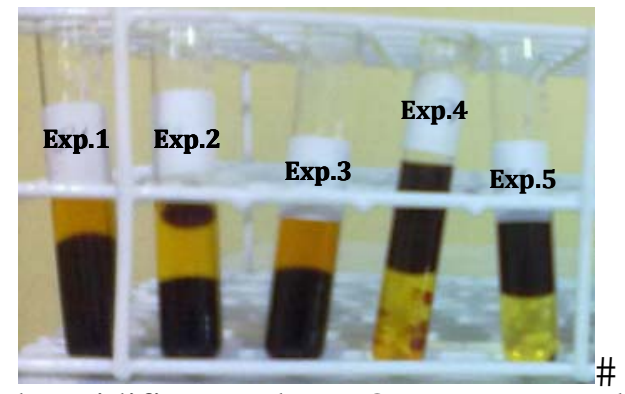

Figura 3 - Experimentos de desacidificação do PLO por extração líquido-líquido empregando álcool etílico com diferentes teores de água.

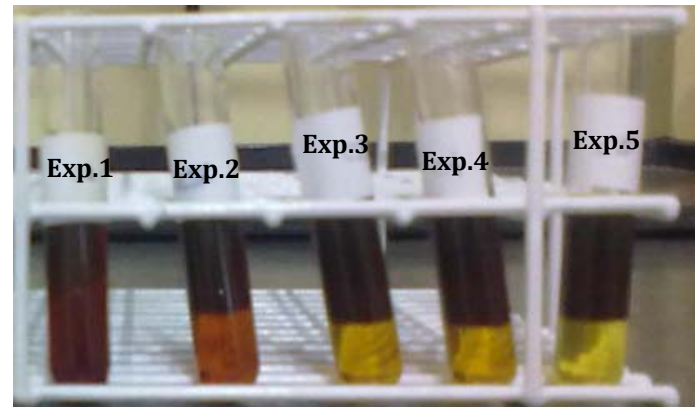

Figura 3 - Experimentos de desacidificação do PLO por extração líquido-líquido empregando álcool isopropílico com diferentes teores de água.

Para ambas as amostras, os melhores resultados deste estudo foram obtidos quando se utilizou álcool etílico com $10 \%$ de água, condição em que o solvente combinado conseguiu 


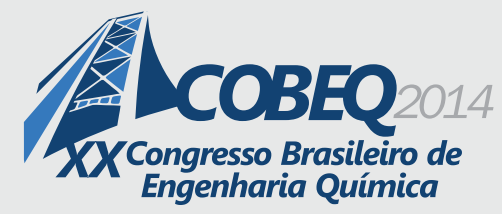

remover um pouco mais de $56 \%$ e $48 \%$ de AGLs para as amostras A e B, respectivamente, e quando se utilizou álcool isopropílico com $20 \%$ de água, condição em que o solvente combinado conseguiu remover em torno de 57 e $42 \%$ de AGLs para as amostras A e B, respectivamente.

\section{CONCLUSÃO}

Através dos resultados obtidos na nos experimentos de desacidificação do PLO através da extração líquido-líquido com dois solventes combinados (álcool etílico/água e álcool isopropílico/água), concluiu-se que o teor inicial de ácidos graxos livres apresenta efeito significativo na remoção destes ácidos por parte do solvente combinado e que, o desempenho do solvente é mais notável em amostras com baixos teores de ácidos graxos livres. Em relação ao teor de água presente nos solventes combinados percebeu-se que o aumento da quantidade de água diminui a quantidade de componentes ácidos removidos, em ambos os solventes aplicados. Além disso, concluiu-se que ambos os solventes combinados utilizados são capazes de reduzir o teor de componentes ácidos do Produto Líquido Orgânico.

\section{REFERÊNCIAS}

FRANK, T. C.; DAHURON, L.; HOLDEN, B. S.; PRINCE, W. D.; SEIBERT, A. F.; WILSON, L. C. Perry's Chemical Engineer's Handbook - Liquid-Liquid Extraction and Other LiquidLiquid Operations and Equipment (Section 15). 8th edition. McGraw-Hill, United States of America, 2008.

\#

PRADO, C.M.R.; ANTONIOSI FILHO N. R. Production and characterization of the biofuels obtained by thermal cracking and thermal catalytic cracking of vegetable oils. J. Anal. Appl. Pyrolysis. V. 86, pag. 338-347, 2009.

QUIRINO, R.L. Estudo do efeito da presença de alumina dopada com $\mathrm{TiO}_{2}$ e $\mathrm{ZrO}_{2}$ no craqueamento do óleo de soja. 2006. 67 f. Dissertação(Mestrado em Química) Universidade de Brasília, Brasília, 2006.

TAUFIQURRAHMI, N.; BHATIA, S. Catalytic cracking of edible and non-edible oils for the production of biofuels. Energy Environ. Sci. v. 4, p. 1087-1112,2011.

TIAN, H.;LI C.; YANG C.; SHAN H. Alternative processing technology for converting vegetable oils and animal fats to clean fuels and light olefins. Chinese Journal of Chemical Engineering, v.16, p. 394-400, 2008. 